\title{
Development and characterization of new XLPE compounds for high performance cables in the automotive industry
}

\author{
Rompante $\mathrm{J}^{1}$, Vieira $\mathrm{A}^{2}$, Amaral F ${ }^{2}$, Pinedo AA ${ }^{3}$, Gonçalves $\mathrm{J}^{1}$, Oliveira $\mathrm{E}^{1}$ and Conceição DS ${ }^{1 *}$ \\ ${ }^{1}$ PIEP, Innovation in Polymer Engineering, Campus of Azurém, Portugal \\ ${ }^{2} \mathrm{ACI}$ Automotive Compounding Industry, Lda, Guarda Industrial Park Lote, Portugal \\ ${ }^{3}$ CMP Automotive Group, Caucho Metal Automotive Group, 26009 Logroño-Espanha, Portugal
}

\begin{abstract}
The materials employed in the electrical insulation of cables/wires used in the automotive industry are exposed to several external factors that may affect the overall performance of the system. These factors include mechanical vibrations, high temperature, humidity, wind and rain. In order to have a stable and trustworthy solution, these materials need to follow specific criteria in what regards their abrasion, thermal and chemical resistance, flame retardancy, and mechanical properties. In this work, new crosslinked polyethylene (XLPE) compounds were developed by means of compound extrusion, using peroxide crosslinking, and also different polymeric matrices. Ultimately, blends of ethylene-vinyl-acetate (EVA) and low density polyethylene (LDPE) with alumina trihydrate (ATH) and magnesium hydroxide (MH), exhibited a significant increase in both the oxidation-induction time - higher than 95 min (OIT), and abrasion resistance (sandpaper abrasion) - approximately 38.1 $\mathrm{g}$, while maintaining a low density profile and fair mechanical properties, when compared with the selected standard material, based on a ATH-additivated EVA material. These findings show that such material can be considered as a promising and suitable candidate for high performance cables.
\end{abstract}

\section{Introduction}

In the automotive industry, the materials commonly used for insulating purposes, of electrical cables and wires, are constantly subjected to external factors such as high mechanical vibrations, high temperature, humidity, wind and rain, that can potentially compromise the overall performance of the system. In order to reach a stable working system, the materials should follow several criteria in what regards their abrasion, thermal and oil resistance, flame retardancy, and mechanical properties, in accordance with specific international standard requirements that, within the scope of this work, were taken into account in the characterization of the developed compounds.

From the polymeric materials commonly used as coatings for electrical cables, three types of classes can be highlighted: the thermoplastic polyester (PBT), the crosslinked polyethylene (XLPE), and the halogenated resins, such as polyvinyl chloride (PVC). In the first case, there are major drawbacks in the utilization of such thermoplastic polyesters, due to temperature and humidity factors; the use of PVC is also being decreased due to its negative environmental impact and, in addition do that, due to thermal degradation above $140^{\circ} \mathrm{C}$, with the release of chloridric acid $(\mathrm{HCl})$. Taking all these considerations into account, polyethylene and its co-polymers rises as a versatile and efficient solution, since it presents a great ease of processing, and a good chemical and mechanical resistance. In order for both polyethylene and its co-polymers (Ethylene vinyl acetate - EVA and Ethylene Butyl Acrylate Copolymer - EBA) to be used in engineeringbased applications, such as electrical insulating cables/wires for the automotive industry, a crosslinking process is often used, to enhance both physical and thermal properties. The chemical crosslinking by using peroxide gives a higher and more uniform degree of crosslinking as compared to physical crosslinking method. In the work of Kim and White, the difference in degree of crosslinking between physical and chemical crosslinking processes is perfectly established [1].
Accordingly, radiation crosslinking yields between $34-75 \%$ degree of crosslinking. In chemical crosslinking method, peroxide gives much high degree of crosslinking (up to 90\%), while silane based crosslinking can be $45-70 \%$ degree of crosslinking.

Regarding the enhancement of the mechanical performance of the system, that can be assured by blends of EVA/LDPE, as referred by Mosnacek et al., [2]. In this case, formulations of chemically crosslinked ethylene vinyl acetate (EVA) and low-density polyethylene (LDPE) blends were prepared. However the polymeric materials used for the above-mentioned applications also need to exhibit an improved flame retardancy and oxidation stability.

The trend to eliminate halogen-based substances to reduce smoke toxicity during combustion lead to halogen free formulations. The addition of magnesium hydroxide $(\mathrm{MH})$ and aluminum trihydrate (ATH) is often used to enable a flame retardant behavior in thermoplastic polymeric matrices, when used as fillers in extrusion compounding.

These metal hydroxides act both in the condensed and the gas phase following endothermic decomposition with water release, which reduces the temperature of the material and surrounding gas phase and dilutes the fuel supply [3]. The use of these metal hydroxides, has been extensively described $[4,5]$.

${ }^{*}$ Correspondence to: David Conceição, PIEP Innovation in Polymer Engineering, University of Minho, Campus of Azurém, 4800-058 Guimarães, Portugal, Tel: +351 253510 065; Fax: +351 253510 059; E-mail: david.conceicao@piep.pt

Key words: compound extrusion, crosslinked polyethylene, high performance materials, electrical insulation, automotive industry

Received: May 20, 2019; Accepted: June 05, 2019; Published: June 10, 2019 
The least expensive, most used, and possibly least toxic flame retardant is ATH and similar inorganic hydrates. However, these materials must be used at very high loadings (sometimes exceeding $60 \%$ by weight). Magnesium hydroxide is an inorganic hydrate that is more thermally stable than ATH. It can be used in PP, PE and similar high melting thermoplastics. Like ATH, MH must also be used at high concentrations to achieve a good flame retardance performance. One of the issues explored in this work was also to achieve a low density material while increasing its thermal stability and flame retardance profile with the inorganic species previously mentioned.

\section{Materials and methods}

EVA Escorene UL00218CC3 with 18\% weight of vinyl acetate from Exxomobil, TPO Fortify POE C30070D from SABIC and LDPE InnoPlus LD2426H from PTT Chemical were used as received. A Non Dust Blend (NDB) antioxidant in pellet (comprising a hindrance phenolic, a phosphide and a metal deactivator) form Altana; processing aids, Bondyram 4108 from Polyram Group, a Silicon Masterbach form Momentive as lubricant and pigment Sachtolith HDS from Sachtleben Chemie $\mathrm{GmbH}$; flame retardants like aluminum hydroxide (ATH) OL104 LEO and magnesium hydroxide(MH) MAGNIFIN H-5 GV from Huber Engineered Materials were used as received. Crosslinking was performed with peroxide Perkadox 14S-fl from Nouryon. In this paper various formulations containing EVA blended with LDPE, TPO and ATH/MH were mixed with co-additives, antioxidants and crosslinking agents, which are described in Table 1.

The additives and resins were pre-mixed without the addition of fillers. In a second phase, a first extrusion of this mixture was carried out in a twin-screw co-rotating extruder (Coperion) with an $\mathrm{L} / \mathrm{D}$ of 40 , and with processing temperatures ranging between $140-200^{\circ} \mathrm{C}$, depending on the material used in each formulation. The incorporation of peroxide was carried out through a second extrusion at $120^{\circ} \mathrm{C}$. Crosslinking was performed by compression molding for 15 minutes, at $180^{\circ} \mathrm{C}$ and 150 bar. Sheets with thicknesses of $2 \mathrm{~mm}$ were prepared and used for all testing methods.

The density of all samples was obtained using an immersion method with propanol as a liquid, at a temperature of $23^{\circ} \mathrm{C}$. Tensile strength and elongation at break were measured using a universal testing machine Shimadzu AG-X, in accordance with ISO 37:2005. The test procedure was carried out using speed of $500 \mathrm{~mm} / \mathrm{min}$ under room temperature conditions. Abrasion by sandpaper was performed using an abrasimeter Taber, model 5155, with H18 wheels and $1000 \mathrm{~g}$ load, in accordance with ISO 9352. The tests were performed under a speed of $60 \mathrm{ver} / \mathrm{min}$, at room temperature conditions. Oxidative Induction Time (OIT) was measured by ASTM D3895-14, using differential scanning calorimetry (DSC), under a constant nitrogen flow and a heating rate of $20^{\circ} \mathrm{C} / \mathrm{min}$ from $30^{\circ} \mathrm{C}$ to $240^{\circ} \mathrm{C}$, maintained at $240^{\circ} \mathrm{C}$ in oxidative atmosphere. The flammability of prepared formulations was characterized by limiting oxygen index (LOI) according to ASTM D 2863.

Table 1. Prepared formulations

\begin{tabular}{|c|c|c|c|c|c|}
\hline $\begin{array}{c}\text { Formulation } \\
\text { Code* }\end{array}$ & C1 & C2 & C3 & C4 & C5 \\
\hline EVA & 40 & 30 & 40 & 40 & 30 \\
\hline TPO & - & 10 & - & - & - \\
\hline LDPE & - & - & - & - & 10 \\
\hline ATH & 54 & 54 & 27 & - & 27 \\
\hline MH & - & - & 27 & 54 & 27 \\
\hline
\end{tabular}

*All formulations contain also 2,5 parts of NDB, 5 parts of Bondyram 4108, 0,65 parts of silicon masterbatch and 1,5 part of Sachtolith HDS.
To evaluate the behavior of the chemical crosslinking, a new set of sheets were prepared by compression molding for 15 minutes, at $120^{\circ} \mathrm{C}$ and 150 bar pressure. The scorch time (T5) of each compound was evaluated according the ASTM D 1646 at $145^{\circ} \mathrm{C}$ in a Mooney Viscometer MR-C3. The optimum crosslinking time (also known as T90) and the degree of crosslinking were obtained by ASTM D 1646 in an Oscillating Disk Rheometer, model Reocheck MD, at $180^{\circ} \mathrm{C}$ during $20 \mathrm{~min}$.

\section{Results and discussion}

The density of all the prepared compounds is shown in Figure 1. It can be observed that the addition of TPO (in C2) and LDPE (in C5), promotes a decrease in the density of the materials, as expected. All formulations are, however, meeting the specification established, taking into account the field of application $\left(\leq 1.4 \mathrm{~g} / \mathrm{cm}^{3}\right)$.

In compound extrusion, one of the key factors is an efficient compatibility between the additives and the polymeric matrix. For that purpose, maleic anhydride was used as the coupling agent between all the additives and the resins from the studied formulations. In addition to that, different ratios of EVA/TPO, and EVA/LDPE, as well ATH/ $\mathrm{MH}$ flame retardants were used. The tensile strength of the compounds explored in this work is shown in Figure 2a. The plot shows that the values obtained for the formulations that contain only ATH (C1-C2), changes between 11-13 MPa and the highest value was achieved for the compound of EVA and ATH, which is the standard sample. However, the increase in the amount of $\mathrm{MH}$ incorporated in the polymeric matrix seems to be adverse and leads to a significant decrease of the tensile strength. Figure $2 \mathrm{~b}$ shows the results of elongation at break of the prepared formulations. It was observed that the elongation at break values were different for ATH and $\mathrm{MH}$-additivated compounds. In the case of formulations with EVA and $\mathrm{ATH}, \mathrm{MH}$ or both, it was observed that with the increase of $\mathrm{MH}$ content, the elongation at break values increased as well (C3 and C4), in comparison with sample C1. However, the formulation $\mathrm{C} 2$ presents an elongation at break higher than $\mathrm{C} 1$, as expected, due to the addition of TPO. On the other hand, the incorporation of LDPE decreased the elongation at break values, abruptly, in comparison with formulation C3. Except for sample C5, all the remaining formulations shows an elongation at break higher than $250 \%$, which is in accordance with the requirements previously established.

Figure 3 exhibits the results of the Shore D hardness tests, and the most interesting ones are obtained in the case of formulations C1, C3 and C5. It was observed that with the addition of TPO, the shore D hardness decreases, as expected, since the TPO has a hardness lower than EVA. Regarding formulation C4, the incorporation of $\mathrm{MH}$ as a flame retardant slightly decreased the shore $\mathrm{D}$ value when compared with compounds $\mathrm{C} 1, \mathrm{C} 3$ and $\mathrm{C} 5$. The incorporation of LDPE did not exhibit any significant effect.

In what regards abrasion by sandpaper, the incorporation of both TPO and MH seems to negatively affect the overall performance of the material, in what regards this specific feature. Indeed, formulation C2 has the lowest abrasion resistance, which can be attributed to the addition of the elastomeric thermoplastic, TPO. On the other hand, when comparing the C3 and C5 formulations, which differ only in the addition of LDPE, there is an abrupt decrease of weight loss, which translates into a high abrasion resistance. Such sample should be considered as a promising candidate in this field of interest. Table 2 summarizes all the obtained results, for the compounds under study. 
Table 2. Characterization of all the samples under study in this work.

\begin{tabular}{|c|c|c|c|c|c|}
\hline $\begin{array}{c}\text { Formulation } \\
\text { Code }\end{array}$ & $\begin{array}{c}\text { Density (g/ } \\
\mathbf{( m}^{\mathbf{3}} \mathbf{a}^{\mathbf{a}}\end{array}$ & $\begin{array}{c}\text { Tensile } \\
\text { Strength } \\
\mathbf{( M P a )}^{\mathbf{b}}\end{array}$ & $\begin{array}{c}\text { Elongation at } \\
\text { break (\%) }^{\mathbf{c}}\end{array}$ & Shore $^{\mathbf{d}}$ & $\begin{array}{c}\text { Abrasion } \\
\text { Resistance }^{\mathbf{( m g})^{\mathbf{e}}}\end{array}$ \\
\hline $\mathbf{C 1}$ & 1,38 & $12,7 \pm 0,7$ & $354 \pm 28$ & $48 \pm 0,4$ & $98,5 \pm 21$ \\
\hline $\mathbf{C 2}$ & 1,33 & $11,5 \pm 0,5$ & $475 \pm 44$ & $43 \pm 0,2$ & $176 \pm 10$ \\
\hline $\mathbf{C 3}$ & 1,37 & $11,7 \pm 0,5$ & $495 \pm 42$ & $47 \pm 0,4$ & $153 \pm 23$ \\
\hline $\mathbf{C 4}$ & 1,37 & $9,4 \pm 0,6$ & $479 \pm 28$ & $44 \pm 0,4$ & $160,7 \pm 41$ \\
\hline $\mathbf{C 5}$ & 1,35 & $11 \pm 0,2$ & $202 \pm 19$ & $47 \pm 0$ & $38,1 \pm 12$ \\
\hline
\end{tabular}

${ }^{\mathrm{a}}$ ISO $1183\left(<1,4 \mathrm{~g} / \mathrm{cm}^{3}\right) ;{ }^{\mathrm{b}} \mathrm{ISO} 37$; ${ }^{\mathrm{C}} \mathrm{SOO} 37(>250 \%)$; ${ }^{\mathrm{d}} \mathrm{ISO} 868$; $\mathrm{e}$ ISO 9352.

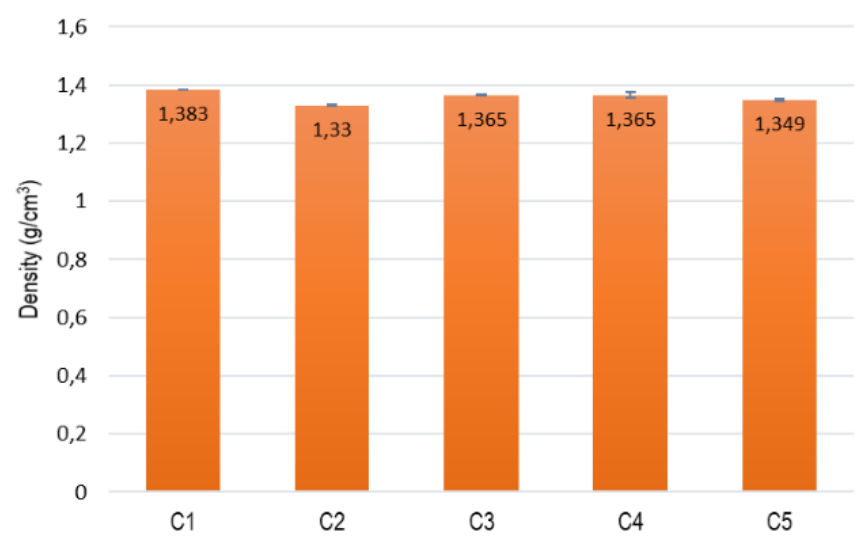

Figure 1. Density measurements of the prepared formulations.

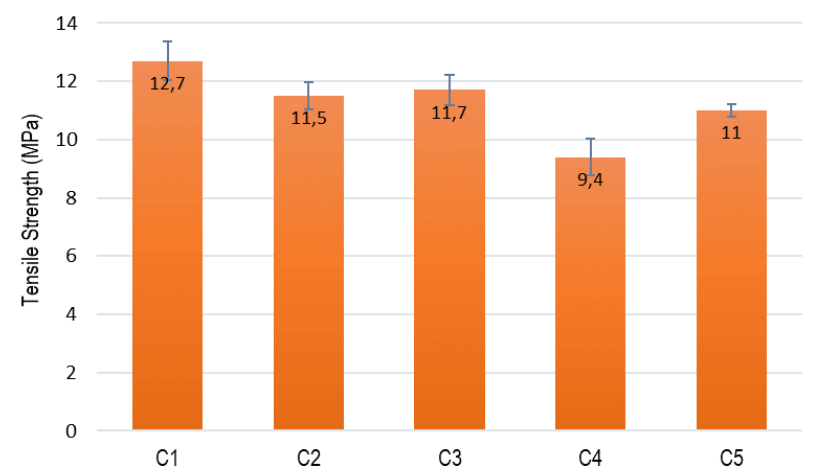

a)

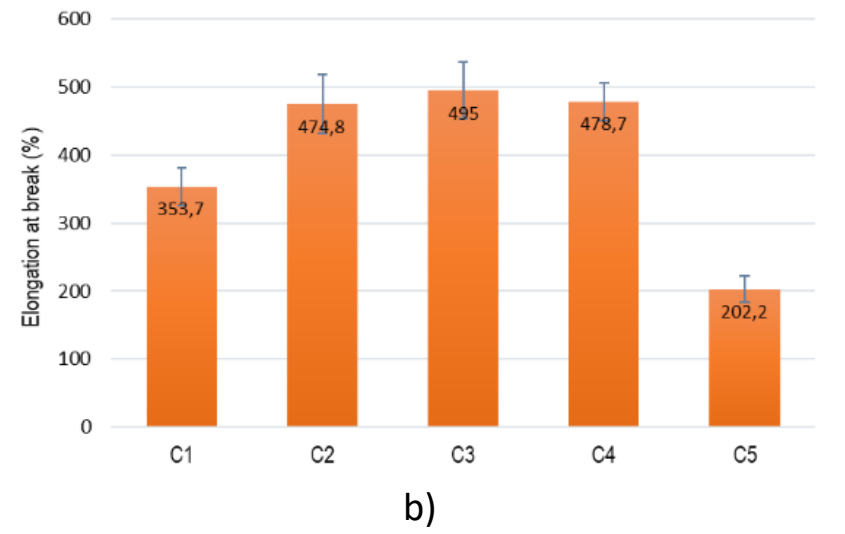

Figure 2. a) Tensile strength and b) elongation at break, of all the prepared formulations.

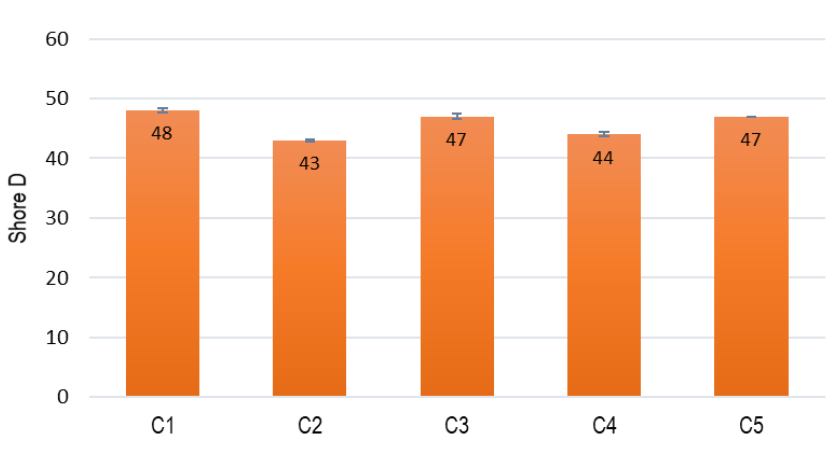

Figure 3. Hardness Shore D of all the prepared formulations.

In order to meet the established requirements, a $75 \mathrm{~min}$ OIT is intended. Formulations $\mathrm{C} 4$ and $\mathrm{C} 5$ have very close values, while C3 holds the best result (Table 3). It was observed that, for the formulations composed with EVA, the increase in the content of $\mathrm{MH}$ rendered a formulation that is abruptly more stable to oxidation, following the required criteria, either in the presence or in the absence of ATH. This improvement was expected and can be justified by the temperature of decomposition of the flame retardants in use, which is $180-200^{\circ} \mathrm{C}$ for $\mathrm{ATH}$, and $300-330^{\circ} \mathrm{C}$ in the case of $\mathrm{MH}[6]$.

The flammability of all the prepared formulations was tested by LOI. This test is widely used to evaluate flame retardancy of materials, especially for screening flame retarded formulations of polymers [2].

It can be seen from Table 4 that addition of metal hydroxides to the polymeric matrix followed by crosslinking leads to a significant increase of LOI up to 28.5 when compared to 18 or $19 \%$ for pure LDPE and pure EVA. The C4 formulation shows the higher LOI result, this phenomenon is explained by the fact that $\mathrm{MH}$ has a high endothermic decomposition temperature in comparison with ATH. In comparison to the fomulation with just EVA, C2 and C5, with TPO and LDPE, respectively, the LOI decreases with the decrease in the contente of EVA. This is due to the fact that the two non-polar polymeric matrices (TPO and LDPE) don't improve the interface filler-matrix like a polar polymer as EVA, leading to a worst flame retardancy effect.

The scorch behavior is especially important at processing temperature [7], in this case $145^{\circ} \mathrm{C}$, the scorch behavior at this temperature, is a key indicator. The summary of all values are present in the Table 5.

The typical safety processing temperature of Perkadox 14S-fl is $\leq 135^{\circ} \mathrm{C}$. As observed in Table 5, all compounds can keep their flow properties during $10 \mathrm{~min}$ at $145^{\circ} \mathrm{C}$, without starting the crosslinking process. The antioxidant, together with a good dispersion of the filler can have a positive effect in this feature. Figure 4 shows a typical Mooney viscosity curve for each compound.

The optimum cure time (T90), minimum torque (ML) and maximum torque $(\mathrm{MH})$ were determined using a moving die rheometer at $180^{\circ} \mathrm{C}$. The torque difference (MH-ML) is directly proportional to the degree of crosslinking, and therefore it is also employed to indirectly represent the crosslinking density of the blend [8].

All formulations show a similar behavior regarding the torque difference (Table 6). This point out to a homogeneous dispersion of the organic peroxide during the second extrusion step. Formulation C3 shows the fast- cure time. The kinetic behavior of each formulation 


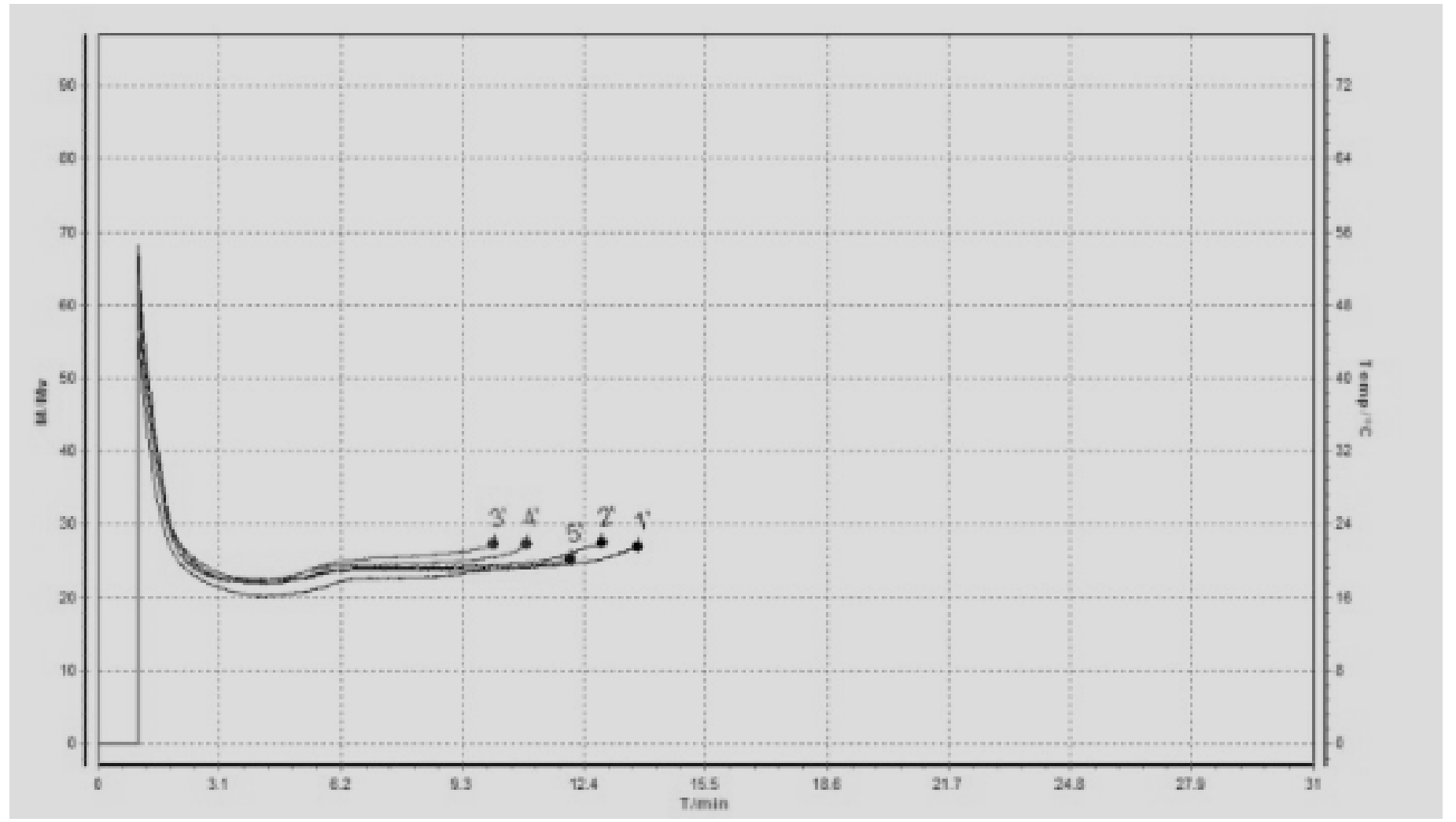

Figure 4. Mooney viscosity curve of prepared formulations

Table 3. OIT of prepared formulations.

\begin{tabular}{|c|c|c|c|c|c|}
\hline \multirow{2}{*}{ OIT $^{\mathbf{a}}(\mathbf{m i n})$} & C1 & C2 & C3 & C4 & C5 \\
\cline { 2 - 6 } & 21 & 29 & $>95$ & 73 & 68 \\
\hline
\end{tabular}

${ }^{\mathrm{a} A S T M}$ D 3895-14 (75 $\left.\mathrm{min}\right)$.

Table 4. LOI of prepared formulations.

\begin{tabular}{|c|c|c|c|c|c|c|c|}
\hline $\begin{array}{c}\text { LOI } \\
\mathbf{( \% )}\end{array}$ & EVA & LDPE & C1 & C2 & C3 & C4 & C5 \\
\cline { 2 - 8 } & 19,0 & 18,0 & 26,3 & 25,8 & 27,6 & 28,5 & 26,8 \\
\hline
\end{tabular}

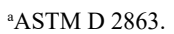

Table 5. Results of Mooney Viscometer ${ }^{\mathrm{a}}$ of prepared formulations.

\begin{tabular}{|c|c|c|c|}
\hline Formulation Code & $\begin{array}{c}\text { MI } \\
\text { (MU) }\end{array}$ & $\begin{array}{c}\text { ML 1+4 } \\
\text { (MU) }\end{array}$ & $\begin{array}{c}\text { T5 } \\
\text { (min) }\end{array}$ \\
\hline C1 & $68 \pm 3$ & $21 \pm 2$ & $13 \pm 3$ \\
\hline C2 & $66 \pm 4$ & $22 \pm 3$ & $11 \pm 2$ \\
\hline C3 & $61 \pm 3$ & $22 \pm 1$ & $9 \pm 3$ \\
\hline C4 & $64 \pm 3$ & $22 \pm 3$ & $11 \pm 3$ \\
\hline C5 & $55 \pm 2$ & $20 \pm 1$ & $12 \pm 2$ \\
\hline
\end{tabular}

${ }^{\mathrm{a} A S T M}$ D 1646

Table 6. Properties obtain in the moving die rheometer test ${ }^{\mathrm{a}}$.

\begin{tabular}{|c|c|c|c|c|}
\hline $\begin{array}{c}\text { Formulation } \\
\text { Code }\end{array}$ & $\begin{array}{c}\text { ML } \\
\mathbf{( d N *} \mathbf{m})\end{array}$ & $\begin{array}{c}\text { MH } \\
\mathbf{( d N *} \mathbf{m})\end{array}$ & $\begin{array}{c}\text { MH -ML } \\
\left(\mathbf{d} \mathbf{N}^{*} \mathbf{m}\right)\end{array}$ & $\begin{array}{c}\text { T90 } \\
\mathbf{( m i n )}\end{array}$ \\
\hline $\mathbf{C 1}$ & 0.39 & 11.07 & 10.68 & 10 \\
\hline $\mathbf{C 2}$ & 0.41 & 10.25 & 9.84 & 9.50 \\
\hline $\mathbf{C 3}$ & 0.42 & 11.09 & 10.67 & 7.24 \\
\hline $\mathbf{C 4}$ & 0.39 & 10.60 & 10.24 & 8.21 \\
\hline $\mathbf{C 5}$ & 0.39 & 11.19 & 10.80 & 10.9 \\
\hline
\end{tabular}

${ }^{\text {aASTM D }} 1646$ found in the moving die rheometer seems to have a direct correlation with the values found in the Mooney viscometer. A short scorch time led to a fast crosslinking time.

\section{Conclusions}

This study evaluated the physical, mechanical and thermal properties of EVA, EVA/LDPE and EVA/TPO with different flame retardants (ATH and $\mathrm{MH}$ ). In this study, taking into account the type of final application, automotive industry, abrasion resistance and thermal stability are the most relevant parameters, whereby the formulations $\mathrm{C} 3, \mathrm{C} 4$ and $\mathrm{C} 5$ have a prominent position in this aspect. The enhancement of mechanical properties, specifically the resistance to abrasion by sandpaper of EVA formulation containing ATH and $\mathrm{MH}$ can be achieved after the addition of a small amount of LDPE (C5). Moreover, in what regards the thermal properties, in relation to the flammability results, no significant differences were observed between the formulations used, therefore can't take accurate conclusions on this test in this case study. However, C5 formulation also exhibits a higher stability to oxidation, and therefore it can be classified as a promising candidate for this type of application, in the automotive industry.

\section{Acknowledgements}

The authors gratefully acknowledge the funding of project $\mathrm{N}^{\circ}$ 24125 - Lightweigth XLPE CE, co-financed by Portugal 2020 and the European Union, through Fundo Europeu de Desenvolvimento Regional (FEDER). 


\section{References}

1. Kim B, White JL (1997) Polymer Engineering and Science. $37^{\text {th }}$ ed.

2. Mosnácek J, Basfar AA, Shukri TM, Bahattab MA (2008) Poly(Ethylene Vinyl Acetate) (EVA)/Low Density Polyethylene (LDPE)/Ammonium Polyphosphate (APP) Composites Cross-linked by Dicumyl Peroxide for Wire and Cable Applications. Polym J vol 40: 460-464

3. Maffezzoli A, Braglia M, De Lazzaro M, Camino G, Zammarano M (2002) Effect of hydroxides and hydroxycarbonate structure on fire retardant effectiveness and mechanical properties in ethylene-vinyl acetate copolymer. Polym Degrad Stab 74 457-464.
4. Rothon RN (1999) Mineral Fillers in thermoplastics: Filler Manufacture and Characterisation. Mineral Fillers in Thermoplastics 139: 67-107.

5. Sauerwein R (2002) New ATH developments drive flame retardant cable compounding Plast Addit Compouding 4: 24-29.

6. Li M, Pang L, Chen M, Xie J, Liu Q (2018) Effects of Aluminum Hydroxide and Layered Double Hydroxide on Asphalt Fire Resistance. Materials (Basel) 11: E1939. [Crossref]

7. Cheremisinoff NP, Chereminisoff PN (1993) Elastomer Technology Handbook, $1^{\text {s }}$ Edition. CRC Press.

8. Sae-oui P, Sirisinha C, Hatthapanit K (2007) Effect of blend ratio on aging, oil and ozone resistance of silica-filled chloroprene rubber/natural rubber (CR/NR) blends. Express Polym Lett 1: 8-14.

Copyright: (C2019 Rompante J. This is an open-access article distributed under the terms of the Creative Commons Attribution License, which permits unrestricted use, distribution, and reproduction in any medium, provided the original author and source are credited. 